\title{
Anchorage loss in corticotomy assisted tooth movement
}

\author{
P.P Biswas ${ }^{1 *}$, Makal Madhav M.P ${ }^{2}$, Navedha ${ }^{3}$, Subairuddeen $\mathbf{P}^{4}$, Priyanka Jayaram ${ }^{5}$ \\ ${ }^{1}$ Professor and HOD, ${ }^{2-5}$ PG Student, Dept. of Orthodontics \& Dentalfacial Orthodontics, KUHS, Royal Dental College, Palakkad, \\ Kerala, India
}

*Corresponding Author: P.P Biswas

Email: makalmadhav@gmail.com

\begin{abstract}
In orthodontic treatment, anchorage loss is a potential side effect of fixed mechanotherapy and one of the major causes of unsuccessful results, on the other hand considerable worry to the orthodontist. A major concern to the orthodontic patients is treatment time. Reducing the treatment time requires increasing the rate of orthodontic tooth movement. Orthodontic force induces a cellular response in the periodontal ligament, which brings about bone resorption on the pressure side and bone deposition on the tension side. Tooth movement can be accelerated by either employing certain adjunctive orthodontic procedures or by using advanced mechanotherapy.

Aim: of this study is to compare and evaluate the anchor loss in corticotomy assisted cases and control cases without corticotomy.

Materials and Methods: The study was conducted among 20 patients who were divided into two groups with 10 cases in each group. Group A patients were treated with corticotomy, allograft procedure along with fixed mechanotherapy while group B patients treated with convectional fixed mechanotherapy and was taken as controls and both groups underwent first bicuspid extractions and were treated with 0.022 MBT appliance.

Result: Corticotomy assisted retraction cases had increased anchorage loss but was statistically insignificant compared to conventional method.

Conclusion: Based on the outcome of this study, it is reasonable to conclude that corticotomy-assisted retraction cases had increased anchorage loss, compared to conventional retraction cases but was stastically insignificant, this may be due to a small sample size. Further studies are recommended on corticotomy-assisted retraction anchorage loss.
\end{abstract}

Keywords: Anchorage loss, Corticotomy, First molar.

\section{Introduction}

Orthodontic tooth movement is a multistep biologic process characterized by sequential reactions of periodontal tissue against biomechanical forces. The recruitment of osteoclast and osteoblast progenitor cells, and the balanced activation of these cells around and within the periodontal ligament (PDL) are essential for alveolar bone remodeling. Various cell-signaling pathways are activated, leading to localized bone turnover. ${ }^{1}$ The rate of orthodontic tooth movement is estimated at 0.8 to $1.2 \mathrm{~mm}$ per month when continuous forces are applied to the teeth. It would take almost two years or more to complete treatment. Accelerating orthodontic tooth movement (OTM) and reducing the length of orthodontic treatment may help to reduce not only discomfort but also possible dental and periodontal complications. The various adjunctive orthodontic procedures used to accelerate tooth movement are mechanical or device asissted methods, chemical methods, surgical methods. Mechanical or device assisted stimulation can be induced by laser irradiation, electric, vibrations etc, Chemical method Vitamin D, Prostaglandin, Interleukins and Surgical methods are corticotomy, dental distraction osteogenesis, micro-osteoperforations.Among various procedure one of the popular method is corticotomy with allografts. $^{2}$

Adult patients who seek orthodontic treatment often desire that their treatment be completed in as short a period as possible. In 1959, Köle introduced a technique called selective alveolar decortications to enable movement of the bone segment ${ }^{3}$. In 2001, Wilcko et al developed a new method of combining corticotomy, alveolar augmentation, and orthodontic treatment. Frost reported that bone remodeling is accelerated and the regional bone density reduced by a noxious stimulus to the bone in a process he termed the Regional acceleratory phenomenon (RAP) which decreases the amount and density of bone around teeth and thereby increases rates of tooth movement. ${ }^{4-6}$ The particulate Corticotomies leads to increased osteoclastic and osteoblastic activity, increased levels of local and systemic inflammation markers in area around cuts that extend to the marrow. Vijayashri Sakthi et $\mathrm{al}^{7}$ states that increased rate of retraction in corticotomy cases when compared to conventional cases (Reduced treatment time), ${ }^{6,8,9,10}$

If anchorage loss anticipated well before it can incooperated into treatment plan to ensure fair results. Orthodontic treatment requiring closure of the extraction space, has side effects such as bone loss, root resorption, gingival recession, root dehiscence, fenestration, caries and white spot lesions can be reduced as treatment time is reduced in corticotomy assisted retraction cases. ${ }^{7}$ Corticotomy assisted retraction helps in resolving crowding, facilitate eruption of impacted teeth, molar intrusion and open bite correction, mesialisation of molars, correction of mild skeletal cases, facilitate slow orthodontic expansion. Corticotomy assisted retraction is contraindicated patients showing any sign of active periodontal disease, individuals with inadequately treated endodontic problems, patients with systemic disease like diabetes mellitus, bleeding disorders, congenital heart disease, uncontrolled hypertension, under prolonged use of corticosteroids. Purpose of this study was to assess the anchorage loss 
anchor molar in corticotomy assisted retraction case and conventional retraction cases.

\section{Materials and Methods}

This study consists of 20 patients, divided into two groups, group A consisting of 10 patients with first bicuspid extractions treated with corticotomy allograft procedure using MBT mechanics and group B consisting of 10 patients treated with $1^{\text {st }}$ bicuspid extractions using regular $022 \mathrm{MBT}$ mechanics which served as control. Utilizing various cephlometric parameters anchor loss (mesial movement) of the first molar was analyzed.

\section{Inclusion criteria}

1. Age group of 10 to 25 years.

2. Patients requiring extraction of the $1^{\text {st }}$ bicuspids.

\section{Exclusion criteria}

1. First molar missing cases were avoided.

2. Periodontally compromised patients.

3. Medically compromised patients and patient under medications systemic for disease like diabetes mellitus, bleeding disorders, congenital heart disease, uncontrolled hypertension.

\section{Method of data collection}

Pre-treatment and post-treatment standardized lateral cephalograms of 10 patients with first bicuspid extractions treated with corticotomy allograft procedure using MBT mechanics were selected cephalograms of 10 patients treated with $1^{\text {st }}$ bicuspid extraction using regular $022 \mathrm{MBT}$ mechanics with transpalatal arch for anchorage were taken as controls. All patients were selected from the record library of the Department of Orthodontics and Dentofacial Orthopaedics, Royal dental college. The anchorage loss was assessed by measuring the position of anchor molar $\left(1^{\text {st }}\right.$ molar) in pre and post treatment tracings of lateral cephalograms, by using four different methods (Superimposition method, Perpendicular $\mathrm{FH}$ to $\mathrm{Xi}$ point method, Pancherz method and Pterygoid vertical method).

\section{Superimposition method}

\section{Maxillary molar}

Superimposition of pre-treatment and post-treatment lateral cephalometric tracings are done. ANS-PNS plane (palatal plane) registered at ANS (Fig. 1).

\section{Mandibular molar}

For assessing the mandibular anchor molar movement pre and post tracings are superimposed on the $\mathrm{Xi}$ point to $\mathrm{Pm}$ plane regesterd at Pm (Fig. 2).

\section{Perpendicular FH to Xi point method}

Horizontal anchor molar movement in upper and lower arch would be determined by the distance between the distobuccal cusp of the anchor molar to a perpendicular drawn from $\mathrm{FH}$ to $\mathrm{Xi}$ point (Fig. 3).

\section{Pterygoid vertical method}

Horizontal anchor molar movement in upper and lower arches would be measured as the distance from the most distal point on the distal surface of the anchor molar to pterygoid vertical (Fig. 4).

\section{Pancherz method}

Horizontal anchor molar movement in upper and lower arches would be measured as distance from the most mesial contact point of anchor molar to the Occlusal line perpendicular (OLP), (Fig. 5).

The molar anchorage loss was compared in the corticotomy group and in the conventional group.

\section{Statistical analysis}

All statistical analyses were performed using SPSS software package (SPSS for Windows XP, version 17.0, Chicago, IL) student $\mathrm{t}$ test was used.

\section{Results}

Rate of anchorage loss in the maxilla and mandible compared to corticotomy group and control group [Table 1 and table 2].

Table 1

\begin{tabular}{|l|c|c|c|c|}
\hline Maxillary Arch & & N & Mean(mm) & Std.Deviation \\
\hline Superimposition & First Bicuspid & 10 & 4.1 & 1.29 \\
\hline Method & Corticotomy & 10 & 4.95 & 1.17 \\
\hline FH perpendicular & First Bicuspid & 10 & 3.9 & 1.07 \\
\hline Method & Corticotomy & 10 & 4.5 & 1.51 \\
\hline Pancherz & First Bicuspid & 10 & 4.15 & 1.27 \\
\hline Method & Corticotomy & 10 & 4.25 & 1.48 \\
\hline Pterygoid vertical & First Bicuspid & 10 & 3.9 & 0.99 \\
\cline { 2 - 5 } Method & Corticotomy & 10 & 4.1 & 1.29 \\
\cline { 2 - 5 }
\end{tabular}

Table 2

\begin{tabular}{|l|c|c|c|c|}
\hline \multicolumn{2}{|l|}{} & Nandibular Arch & Mean(mm) & Std. Deviation \\
\hline \multirow{2}{*}{$\begin{array}{l}\text { Superimposition } \\
\text { Method }\end{array}$} & First Bicuspid & 10 & 3.1 & 0.77 \\
\cline { 2 - 4 } & Corticotomy & 10 & 4.45 & 0.86 \\
\hline FH perpendicular & First Bicuspid & 10 & 3.1 & 1.02 \\
\hline
\end{tabular}




\begin{tabular}{|l|c|c|c|c|}
\hline Method & Corticotomy & 10 & 3.6 & 0.99 \\
\hline Pancherz & First Bicuspid & 10 & 3.3 & 0.92 \\
\cline { 2 - 5 } Method & Corticotomy & 10 & 4 & 1.15 \\
\hline Pterygoid vertical & First Bicuspid & 10 & 3.15 & 0.97 \\
\cline { 2 - 5 } Method & Corticotomy & 10 & 4 & 1.25 \\
\hline
\end{tabular}

\section{Anchorage loss}

\section{Maxilla}

Corticotomy group showed increased anchorage loss in all four methods and difference was statistically insignificant compared to control group

\section{Mandible}

Corticotomy group showed increased anchorage loss in all four methods and difference was statistically insignificant except for superimposition method compared to control group superimposition method $\mathrm{p}$ value $0.002(\mathrm{p}$ value $<0.005$ ) was significant.

\section{Anchor loss}

\section{Maxilla}

Average molar anchor loss of approximately $4.5 \mathrm{~mm}$ occurred in the study group, and $4.1 \mathrm{~mm}$ occurred in the control group.

\section{Mandible}

Average molar anchor loss of approximately $4.0 \mathrm{~mm}$ occurred in the study group, and $3.2 \mathrm{~mm}$ occurred in the control group.

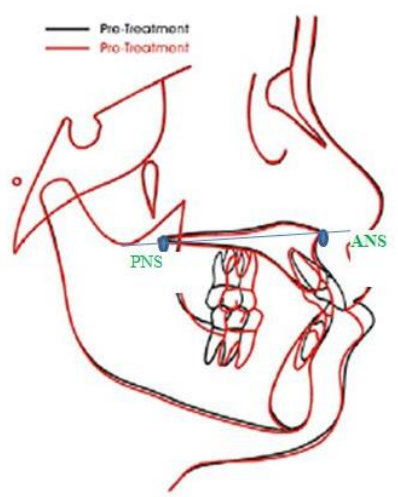

Fig. 1: Superimposition method Maxillary arch

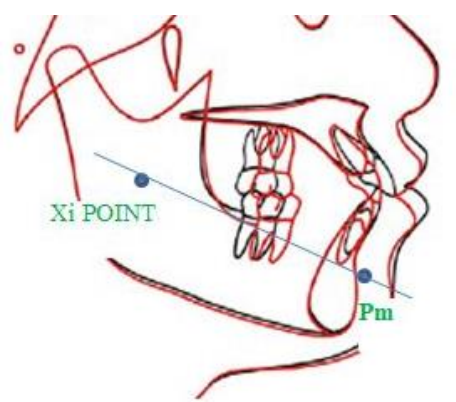

Fig. 2: Superimposition method Mandibular arch

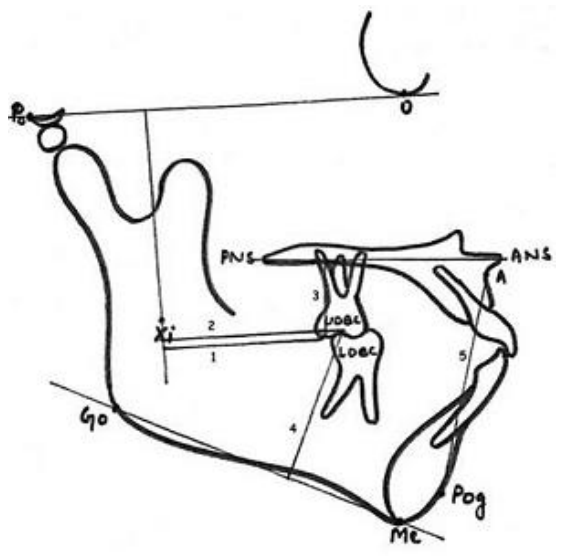

Fig. 3: Perpendicular FH to Xi point method

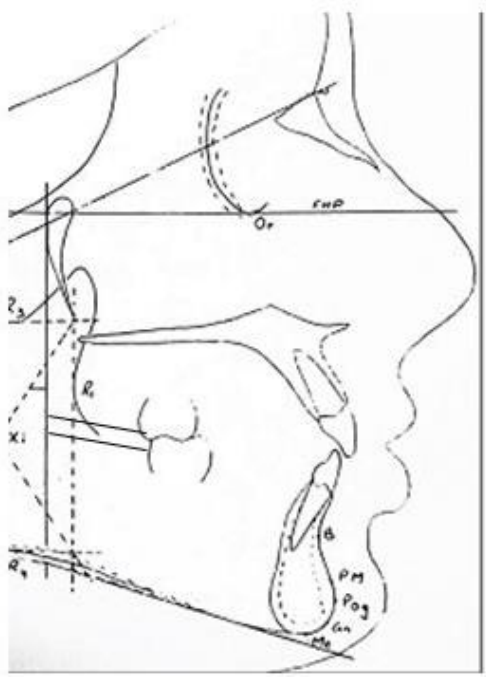

Fig. 4: Pterygoid vertical method

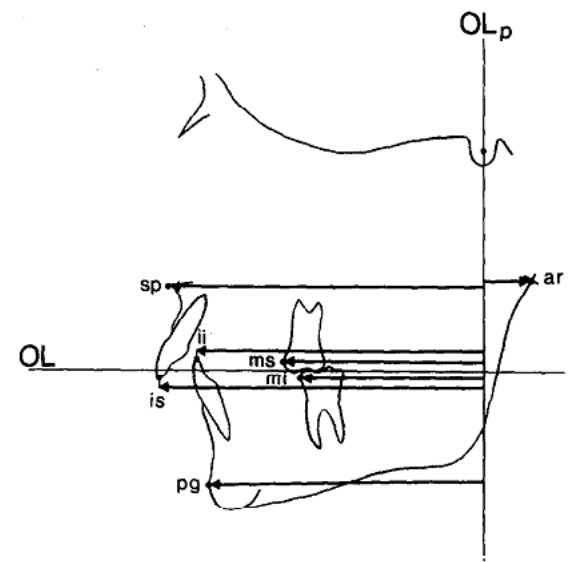

Fig. 5: Pancherz method 


\section{Discussion}

In orthodontics the common treatment, approach usually consists of extraction of four first bicuspids for maximum anchorage cases. Corticotomy is an effective and safe procedure to accelerate orthodontic tooth movement. Additionally, to other procedures for accelerated tooth movement, corticotomy is the most commonly used approach. There is sufficient evidence in the literature by Wilcko et al and many others suggesting that the corticotomy procedure shortens the conventional orthodontic treatment time, and it has been claimed that teeth can be moved two to three times faster. ${ }^{6-10}$ Thus, to take advantage of the maximum regional acceleratory phenomenon on which an average exists for four months, ${ }^{6,8}$ delayed extraction of the first bicuspids just before retraction would be advantageous in accelerating tooth movement in protrusion cases. This protocol has been used effectively to enhance the en-masse retraction of the anterior segment compared with the conventional en-masse retraction in bimaxillary protrusion patients. The teeth were retracted with stainless steel wire $(0.019 " \times 0.025$ ") to minimize torque loss and to bring about bodily movements during retraction. The posterior segment (second premolar, first and second molar) was not decorticated to enable them to serve as an anchorage unit.

Molar anchor loss has not been documented convincingly in the literature for corticotomy assisted retraction. Therefore, our study aimed to evaluate the molar anchor loss that occurred in the study group and control group.

Conventional corticotomy ${ }^{6}$ both buccal and lingual plates are perforated in surgical procedure of corticotomy as was the case in this study. Michele Cassettaa et $\mathrm{al}^{11}$ perforated only the buccal and labial cortical plate siting advantages like and to avoiding the lingual surface reduce operation time and postoperative patient discomfort. It also avoid the risk of damaging vital lingual structures. Microosteoperforation is carried out without flap elevation but it uses a special instrument Profel for Micro-osteoperforation. ${ }^{1}$

Anchor loss was assessed with the help of lateral cephalogram taken pretreatment and post treatment anchorage loss was measured using four different methods Superimposition method, Perpendicular $\mathrm{FH}$ to $\mathrm{Xi}$ point method, Pterygoid vertical method, pancherz method. An increased anchorage loss was present in the corticotomy group compared to the control group, an average of $4.5 \mathrm{~mm}$ in the maxilla and $4.0 \mathrm{~mm}$ in the mandible for corticotomy group and an average of $4.1 \mathrm{~mm}$ in the maxilla and $3.2 \mathrm{~mm}$ in the mandible in the control group. The probable reason for increased anchorage loss in corticotomy cases would be that activation was done in every two weeks whereas in control group activation was done in six weeks of time. A study by Vijayashri Sakthi et $\mathrm{al}^{7}$ is also in agreement with the present study suggesting the occurrence of anchor loss with corticotomy. Most studies have micro implant assisted anchorage for anterior retraction and thus anchorloss comprasion would not be justified.

\section{Summary and Conclusion}

Based on the outcome of this study, it is reasonable to conclude that corticotomy-assisted retraction cases had increased anchorage loss, compared to conventional retraction cases but was stastically insignificant, this may be due to a small sample size. Further studies are recommended on corticotomy-assisted retraction anchorage loss.

\section{Source of Funding}

None.

\section{Conflict of Interest}

None.

References

1. Sugimori T, Yamaguchi M, Shimizu M, Kikuta J, Hikida T, Hikida M, et al. Micro-osteoperforations accelerate orthodontic tooth movement by stimulating periodontal ligament cell cycles. Am J Orthod Dentofac Orthop. 2018;154(6):788-96.

2. Brugnami F, Caiazzo A, Mehra P. Can corticotomy (with or without bone grafting) expand the limits of safe orthodontic therapy? JOral Biol Craniofac Res 2018;8:1-6

3. Köle H. Surgical operations on the alveolar ridge to correct occlusal abnormalities. Oral Surg Oral Med Oral Pathol. 1959;12(5):515-29.

4. Murphy KG, Wilcko MT, Wilcko WM, Ferguson DJ. Periodontal accelerated osteogenic orthodontics: a description of the surgical technique. J Oral Maxillofac Surg. 2009;67(10):2160-6.

5. Frost HM. The regional acceleratory phenomenon: a review. Henry Ford Hosp Med J. 1983;31(1):3-9.

6. Wilcko MT, Wilcko WM, Bissada NF. An Evidence-Based Analysis of Periodontally Accelerated Orthodontic and Osteogenic Techniques: A Synthesis of Scientific Perspectives. Semin Orthod. 2008;14(4):305-16.

7. Sakthi SV, Vikraman B, Shobana VR, Iyer SK, Krishnaswamy NR. Corticotomy-assisted retraction: An outcome assessment. Indian J Dent Res. 2014;25:748-54.

8. Wilcko WM, Wilcko MT, Bouquot JE, Ferguson DJ. Rapid orthodontics with alveolar reshaping: two case reports of decrowding. Int J Periodont Restor Dent. 2001;21(1):9-19.

9. Ferguson DJ, Wilcko WM, Wilcko MT. Selective Alveolar Decortication for rapid surgical-orthodontic of skeletal malocclusion treatment. In: William HB, Cesar AG, editors BC Decker Inc, Hamilton; 2007:199-203.

10. Gantes B, Rathbun E, Anholm M. Effects on the periodontium following corticotomy-facilitated orthodontics. Case reports. $J$ Periodontol. 1990;61(4):234-8.

11. Cassetta M, Altieri F, Barbato E. The combined use of corticotomy and clear aligners: a case report. Angle Orthod. 2016;86(5):862-70

12. Aboul-Ela SM, El-Beialy AR, El-Sayed KM, Selim EM, ElMangoury NH, Mostafa YA. Miniscrew implant-supported maxillary canine retraction with and without corticotomyfacilitated orthodontics. Am J Orthod Dentofacial Orthop. 2011;139:252-9.

13. Wilcko WM, Wilcko T, Bouquot JE, Ferguson DJ. Rapid orthodontics with alveolar reshaping: two case reports of decrowding. Int J Periodontics Restorative Dent. 2011;21:919.

14. Wilcko W, Wilcko MT. Accelerating tooth movement: the case for corticotomy-induced orthodontics. Am J Orthod Dentofacial Orthop. 2013;144:4-12. 
15. Sanjideh PA, Rossouw PE, Campbell PM, Opperman LA, Buschang PH. Tooth movements in foxhounds after one or two alveolar corticotomies. Eur J Orthod. 2010;32:106-13.

16. Hosl E, Baldauf A. Mechanical and Biological Basics in Orthodontic Therapy. Heidelberg: Hüthig Buch Verlag; 1991. p. $207-26$
How to cite this article: Biswas PP, Madhav MMP, Navedha, Subairuddeen P, Jayaram P. Anchorage loss in corticotomy assisted tooth movement. Int J Oral Health Dent 2020;6(1):36-40. 